1 Universidade Federal do Rio de Janeiro (UFRJ), Instituto de Economia, PósGraduação em Economia Política Internacional - Rio de Janeiro (RJ), Brasil. padula.raphael@gmail.com

\section{BRICS: potencialidades de cooperação e papel na governança global de saúde no contexto da pandemia}

\author{
BRICS: potential for cooperation and role in global health governance \\ in the pandemic frame
}

Raphael Padula', Felipe de Carvalho Borges da Fonseca' ${ }^{\mathbf{1}}$
RESUMO O argumento central do artigo é de que os países do BRICS vinham consolidando e ampliando sua cooperação na área da saúde, na qual há importantes complementaridades, que, ao atuarem coordenadamente, contribuem para instalar novas dinâmicas de poder no campo da saúde internacional que desafiam interesses dos Estados e suas empresas transnacionais que concentram esse mercado, especialmente no cenário de pandemia global. O setor saúde é abordado de forma ampla, mas com foco especial na indústria farmacêutica, setor considerado político-estratégico por ser fundamental para a estabilidade política, desenvolvimento socioeconômico e segurança nacional. O artigo apresenta considerações sobre a estratégia estadunidense de segurança nacional no que se refere à saúde. Em seguida trata das vulnerabilidades e potencialidades de cooperação em saúde dos países do BRICS em termos de mercado e acesso universal à saúde, acesso a tecnologias e combate a doenças negligenciadas, relação do Bloco com a governança global em saúde, e finalmente do contexto pandêmico e da geopolítica da vacina. O texto se apoia em informações e dados de instituições especializadas em saúde, documentos de governos ou dos BRICS, e bibliografia de autores especialistas em saúde global.

PALAVRAS-CHAVE BRICS. Organização Mundial da Saúde. Cooperação internacional. Infecções por coronavírus. Tuberculose.

\begin{abstract}
The main argument of the article is that the BRICS countries have been consolidating and expanding their cooperation in the area of health, in which they show important complementarities, and that, by acting in coordination, they contribute to establish a new power dynamic in the field of international health that challenge interests of the States and their Transnational Companies that concentrate this market, especially in the pandemic global frame. The health sector is widely approached, but with a special focus on the pharmaceutical industry, a sector considered as strategic because it is fundamental for political stability, socioeconomic development and national security. The article presents considerations on the American national security strategy regarding health. It then addresses the vulnerabilities and potential for health cooperation in the BRICS countries in terms of market and universal access to health, access to technologies and combating neglected diseases, the bloc's relationship with global governance in health, and finally concerning the pandemic scenario and the geopolitics of vaccines. It is based on information and data from specialized health institutions, government or BRICS documents, and in a bibliography of authors specialized in international health.
\end{abstract}

KEYWORDS BRICS. World Health Organization. International cooperation. Coronavirus infections. Tuberculosis. 


\section{Introdução}

A pandemia de Covid-19 traz consigo dinâmicas de poder relevantes para a discussão de conceitos relativamente recentes no repertório político e na literatura, tais como 'saúde global', 'bens públicos globais', 'governança global em saúde' e 'diplomacia da saúde'1, que denotam uma crescente importância da saúde nas relações internacionais e a necessidade de maior coordenação entre governos e atores não-estatais na resposta a desafios comuns. Entretanto, revisões de literatura têm apontado que há pouca discussão dos fatores que impulsionaram essa mudança, bem como pouca compreensão sobre como as relações de poder presentes no sistema internacional interferem no alcance de determinados objetivos de saúde global ${ }^{2}$.

Nesse sentido, este artigo aborda como a agenda de saúde estabelecida pela coalizão dos BRICS se insere em tais dinâmicas de poder. O BRICS é um Bloco de países formado por Brasil, Rússia, Índia, China e África do Sul, originado inicialmente como um conceito para se referir ao significativo crescimento dessas economias entre 2000 e 2010. A coordenação política entre Brasil, Rússia, Índia e China (BRIC) iniciou-se de maneira informal em 2006, por meio de reunião de trabalho entre os chanceleres dos quatro países à margem da Assembleia Geral das Nações Unidas. Em 2009, foi realizada a primeira cúpula de chefes de estado desses quatro países, que são realizadas anualmente desde então. Em 2011, a África do Sul foi integrada ao Bloco. Hoje, onze anos após a formalização do mecanismo, mais de trinta áreas de cooperação foram estabelecidas, sendo a da saúde uma das mais promissoras, conforme iremos argumentar. Cabe destacar ainda que a cooperação BRICS deu origem a duas instituições no campo financeiro: o Novo Banco de Desenvolvimento (NDB) e o Arranjo Contingente de Reservas (ACR).

Para caracterizar essa atuação conjunta dos BRICS no campo da saúde global, foram analisadas nove declarações das cúpulas presidenciais, nove declarações das cúpulas ministeriais de saúde, seis comunicados ministeriais emitidos durante as assembleias mundiais de saúde e os resultados dos três editais do Programa Quadro de Cooperação em Ciência, Tecnologia e Inovação dos BRICS lançados entre 2016 e 2019. Além disso, foram analisadas declarações e ações tomadas pelos BRICS no contexto da pandemia de Covid-19.

Individualmente, os países dos BRICS também possuem grande peso como mercados consumidores de produtos farmacêuticos e, de maneira crescente, como desenvolvedores e produtores desses mesmos mercados. Essa dupla característica é um fator que gera tensões em áreas como a de propriedade intelectual, onde, na condição de mercados emergentes, os países sofrem pressões de países desenvolvidos pela adoção de regras mais estritas de patenteamento e, na condição de exportadores de versões genéricas, necessitam de regras mais flexíveis. A capacidade de inovação e produção presente nos BRICS também pode desempenhar um papel relevante na resposta global à Covid-19.

Embora não seja uma tendência recente, a indústria farmacêutica global vem passando por um processo de crescente concentração favorável aos países desenvolvidos - Estados Unidos da América (EUA), Europa e Japão e suas grandes empresas. Ao longo dos anos 2000, em um amplo processo de fusões e aquisições, as grandes empresas transnacionais do setor aprofundaram a convergência entre indústria farmacêutica e indústria biotecnológica voltada à saúde ${ }^{3}$.

O BRICS, por sua vez, vem desempenhando um papel de contraposição ao modelo de concentração do mercado farmacêutico global. Sob a ótica da Economia Política Internacional, tal cooperação em saúde pode ser compreendida por meio da possibilidade de alçar o BRICS a uma posição influente nas discussões sobre saúde global, com potenciais impactos econômicos e político-estratégicos, inclusive na redução de vulnerabilidades para os países membros. 
A cooperação intra-BRICS em saúde se construiu com base no fato de que esses países:

enfrentam desafios similares de saúde pública, incluindo acesso universal a serviços de saúde, acesso a tecnologias de saúde, dentre as quais medicamentos, e o aumento de custos e da carga tanto de doenças infecciosas como crônicas ${ }^{4}$.

Além do combate às chamadas doenças negligenciadas. É nesse sentido que esse Bloco reúne forte potencial de influenciar um amplo conjunto de políticas de saúde, buscando resolver problemas comuns e liderando iniciativas em favor dos países do Sul Global - de renda média e baixa -, de maior vulnerabilidade externa nos campos político-militar e socioeconômico. Isso se torna ainda mais relevante no contexto atual de pandemia de Covid-19, no qual as vulnerabilidades dos países do Sul Global ficam mais explícitas, ao mesmo tempo em que a competição política em torno da saúde e da supremacia de poder global se acelera, até mesmo no caso das vacinas e seus arranjos de cooperação e acesso.

Este texto analisa aspectos da cooperação em saúde dos BRICS, destacando, em especial, suas implicações políticas. $\mathrm{O}$ argumento central é o de que os países do Bloco têm importantes complementaridades no campo da saúde e que, ao atuarem coordenadamente, contribuem para novas dinâmicas de poder no campo da saúde global, que desafiam os interesses dos Estados e suas empresas transnacionais que concentram este mercado, especialmente nos casos do acesso a tecnologias e de impactos na governança global em saúde, ficando ainda mais evidente no contexto da pandemia atual. Por ser hoje a maior potência global, sede de seis das dez maiores empresas farmacêuticas globais, o epicentro da inovação no setor farmacêutico e o maior promotor de regras internacionais de propriedade intelectual, os EUA constituem um elemento fundamental de análise para compreender esse setor, bem como as vulnerabilidades estratégicas projetadas sobre outros países ${ }^{5}$.
Gadelha e Silveira ${ }^{6}$ propõe o conceito de Complexo Econômico-Industrial da Saúde (Ceis), que considera a conexão entre os diferentes setores de saúde e de serviços de saúde, relevando as divergências de interesses entre atores públicos e privados, internos e externos, nos sistemas públicos de saúde nacionais. Aqui, o setor saúde é abordado de forma ampla, mas com foco na indústria farmacêutica, setor considerado político-estratégico por ser fundamental para a estabilidade política, desenvolvimento socioeconômico e segurança nacional de um Estado7. A competição interestatal, em um sistema internacional caracterizado por assimetrias de poder e riqueza e conflito de interesses, também reflete no campo da saúde. Padula7 afirma que a busca por uma economia nacional mais diversificada e menos dependente das relações exteriores, particularmente em bens industriais e estratégicos, é encarada como um fator que contribui para a independência política ou autonomia estratégica do Estado no sistema internacional por meio da redução de suas vulnerabilidades externas.

Nesse sentido, Padula apresenta o conceito de segurança de saúde como a capacidade de um Estado ter acesso garantido a recursos em bens, serviços e tecnologia, financiamento e mercados na área de saúde, necessários à sustentação de níveis aceitáveis de bem-estar social e poder estatal ou para sua autonomia política. Ainda, a segurança de saúde pode ser vista como a capacidade de uma economia nacional de produzir internamente os bens e serviços de saúde que atendam às necessidades de sua população, de forma a universalizar o acesso tanto em tempos de paz como de conflitos político-econômicos. Depende, assim, do domínio de tecnologias, da capacidade financeira e produtiva e de mobilização de recursos em tempo hábil.

Entretanto, a busca pela autonomia nacional envolve conflitos de interesses interestatais, com afirma Padula, pois Estados poderosos atuam de acordo com os interesses das suas empresas e da manutenção de assimetrias 
estruturais no sistema internacional, promovendo acordos e utilizando sua influência em organizações internacionais como forma de legitimar seus interesses, construindo regras que lhes sejam favoráveis para acessar mercados e recursos estratégicos. Por outro lado, para alterar suas condições de vulnerabilidade, os países em desenvolvimento ou posição inferior precisam confrontar a distribuição assimétrica de poder no sistema interestatal, desafiando ou buscando mudar princípios, normas e regras que são de interesse das grandes potências e suas corporações. No contexto atual, no qual os EUA buscam manter sua posição de maior potência global, a China se destaca como seu principal desafiante, e a aliança sino-russa vem buscando uma distribuição de poder menos concentrada no sistema internacional. Tal conflito estrutural tende a ficar mais evidente nas instituições internacionais.

Para comprovar o argumento central e caracterizar esse conflito estrutural, o texto se divide em seis seções, além desta Introdução. Primeiro, são apresentadas considerações sobre a estratégia norte-americana de segurança nacional no que se refere à saúde. $\mathrm{A}$ segunda seção trata das vulnerabilidades em saúde nos BRICS, enquanto a terceira aborda seu potencial de articulação em torno de interesses sanitários, econômicos e políticos comuns. A quarta analisa a relação dos BRICS com a governança global em Saúde. A quinta aborda a atuação dos BRICS no contexto da pandemia de Covid-19. A última dedica-se a considerações finais e conclusões. O texto se apoia em informações e dados de instituições especializadas em saúde, em documentos de governos ou dos BRICS e em bibliografia de autores especialistas em saúde global.

\section{Saúde na estratégia dos EUA}

McInnes 8 identifica, a partir dos anos 1990, a consolidação de um processo de ampliação da agenda de segurança, onde uma gama maior de riscos é considerada, para além das ameaças eminentemente militares. Nessa conjuntura, a saúde passou a ser percebida como uma questão de segurança, levando-se em consideração especialmente as doenças infecciosas, as pandemias e o bioterrorismo.

Nos EUA, diversos documentos da área de inteligência classificam as doenças infecciosas como um grande risco para cidadãos americanos dentro e fora do País, para militares americanos em operação e como um fator gerador de instabilidade em países e regiões onde os EUA têm interesses. No documento do Conselho Nacional de Inteligência' 'A Ameaça Global das Doenças Infecciosas e suas Implicações para os EUA', as doenças infecciosas consideradas mais ameaçadoras para os EUA no período de 2000 a 2020 são HIV/ Aids, Tuberculose, Hepatite C, patógenos com alto nível de resistência à antibióticos, como o Staphylococcus aureus, e variedades novas e mais letais da Influenza.

Ao analisar outros países e regiões do mundo, os relatórios e estudos da inteligência estadunidense concluem que uma carga elevada e contínua de doenças infecciosas é associada com deterioração econômica, fragmentação social e desestabilização política, com impactos na produtividade, renda e investimentos ${ }^{10}$. Do mesmo modo, outros documentos estratégicos concluem que o aumento da carga de doenças crônicas impacta a economia, a legitimidade de governos e a capacidade militar de países e regiões geopoliticamente relevantes ${ }^{11}$. Acesso limitado a cuidados de saúde para prevenir ou tratar tais doenças, bem como uma baixa qualidade dos serviços, tende a intensificar as divisões sociais, que são um fator relevante de instabilidade política. Do ponto de vista estratégico, o principal impacto de uma resposta de saúde insuficiente é o efeito nas gerações mais jovens, cuja debilitação tem impacto direto no efetivo militar e na capacidade de prontidão das tropas.

O Centro Nacional de Inteligência Médica (NCMI), vinculado à Agência de Inteligência da Defesa (DIA) do Departamento de Defesa 
dos EUA, desenvolveu um ranking em 2000, e atualizado em 2008 , de capacidades em cuidados de saúde, dividindo os países em categorias de 1 a 5, sendo 1 'Excelente', 2 'Bom', 3 'Regular', 4 ‘Ruim' e 5 'Inapropriado'. A análise leva em consideração a infraestrutura de saúde no País, a disponibilidade de produtos farmacêuticos e outros bens de saúde, os recursos orçamentários destinados à saúde e o nível de prioridade política dada ao tema. Nesse levantamento, Brasil, Índia e China aparecem como 'ruins', Rússia como 'regular' e África do Sul como 'bom'10.

Essa análise tem duas funções. A primeira é identificar vulnerabilidades de saúde em países de importância estratégica, cuja superação possa ser explorada, dentre outras coisas, para ampliar a aceitação dos EUA em esforços de reconstrução e estabilização em contextos de conflito, como uma estratégia de 'diplomacia pela porta dos fundos' para reduzir tensões com adversários e para aumentar a cooperação e engajamento com poderes emergentes. A segunda é justificar um papel de intervenção passível de ser exercido pelos EUA a pretexto de 'combater ameaças biológicas e pandemias' em seu ponto de origem"

Na Estratégia de Segurança Nacional (NSS) em vigor nos EUA, a competição com outras potências é um tema central, sendo que a Rússia e a China vêm sendo colocadas como principais preocupações desde os documentos estratégicos do governo de Barack Obama ${ }^{12}$. A Estratégia Nacional de Defesa de $2018^{13}$ assevera ainda que a proliferação do conhecimento está erodindo as vantagens históricas dos EUA e que esse processo precisa ser revertido em nome da segurança e da prosperidade estadunidense. Nesse sentido, a NSS de $2017^{14}$ prevê como ação prioritária, além de detectar e conter ameaças biológicas em sua origem e melhorar a resposta a emergências, apoiar a inovação biomédica.

Em relação à pesquisa biomédica em particular, enfatiza-se o fortalecimento do sistema de propriedade intelectual, considerado 'a base da indústria biomédica'. A NSS fala ainda em 'promover e proteger a Base de Inovação em Segurança Nacional (NSIB)', tendo como ação prioritária a proteção da propriedade intelectual. A estratégia promete combater a apropriação ilícita de conhecimento técnico e tecnológico do setor público e privado estadunidense por competidores externos e dedicar esforços de contra inteligência para acabar com 'roubo de propriedade intelectual'. Nessa estratégia, os EUA evidenciam que, com o intuito de 'liderar em pesquisa, tecnologia, invenção e inovação', realizará esforços de monitoramento de pesquisas em curso em outros países, inclusive na área biomédica, de forma a proteger as vantagens dos EUA sobre seus competidores.

Vale destacar que o Defense Advanced Research Projects Agency (Darpa), subordinado ao Departamento de Defesa e cuja missão é a de liderar a criação de novas tecnologias para segurança nacional, historicamente, tem dado grande relevância a tecnologias da área de saúde. Em 2014, por exemplo, foi criado um escritório específico para dar ênfase à biologia - o Biological Technologies Office (BTO). Na visão estratégica do Darpa, para criar surpresa tecnológica e 'vantagens de vanguarda', são essenciais a superação das doenças infecciosas, a neurotecnologia e a biologia sintética. Dentre as vacinas mais avançadas para Covid-19, está a da empresa norte-americana Moderna, que usa o RNA mensageiro (mRNA), uma nova fronteira tecnológica nunca antes aplicada em vacinas. Desde 2013, a Moderna tem sido financiada pelo Darpa para construir sua plataforma de mRNA para desenvolver vacinas para infecções virais.

Nessa competição tecnológica, os EUA têm a China como principal oponente. O governo chinês designou a biotecnologia como indústria prioritária em seu $13^{\circ}$ plano quinquenal e na iniciativa 'Made in China 2025', com amplo apoio estatal para as empresas domésticas. Além disso, de acordo com a Organização Mundial de Propriedade Intelectual (Ompi), em 2019, a China assumiu a liderança do ranking mundial de patenteamento, posição 
detida pelos EUA desde 1978, quando o Tratado de Cooperação em Patentes (PCT) foi estabelecido. Como veremos adiante, o tema das patentes é um eixo crucial da disputa tecnológica entre China e EUA na área biofarmacêutica.

\section{Vulnerabilidades em saúde nos BRICS}

Em 2016, o BRICS concentrava 41,2\% da população mundial e cerca de $30 \%$ do território mundial em 2017, o BRICS respondia por 23,6\% do Produto Interno Bruto (PIB) mundial ${ }^{15}$. Entretanto, os países do BRICS possuem diferenças marcantes em seus indicadores socioeconômicos e estrutura de gastos públicos, conforme mostra a tabela 1, além de diferenças em projeção política e poderio militar. Rússia e China são potências milenares detentoras de arsenal nuclear, sendo a China a atual potência desafiante à supremacia global dos EUA, assim como foi a Rússia no período da Guerra Fria. A Índia também possui artefatos militares nucleares.

Tabela 1. Dados relevantes em saúde dos países do BRICS

\begin{tabular}{|c|c|c|c|c|c|}
\hline Dado & Brasil & China & Índia & Rússia & África do Sul \\
\hline População total (2018) & 209.469 .333 & 1.393 .000 .000 & 1.353 .000 .000 & 144.478 .050 & 57.779 .622 \\
\hline Expectativa de Vida ao nascer (2017) & 75.72 & 76.41 & 68.80 & 72.11 & 63.40 \\
\hline $\begin{array}{l}\text { Taxa de mortalidade de menores de cinco anos (por } 1.000 \\
\text { nascidos vivos) (2017) }\end{array}$ & 14,8 & 9,3 & 39,40 & 7,6 & 37,10 \\
\hline Gastos em saúde em \% do PIB (2016) & 11,77 & 4,98 & 3,65 & 5,27 & 8,11 \\
\hline $\begin{array}{l}\text { Gasto doméstico em saúde como \% dos gastos atuais em } \\
\text { saúde (2016) }\end{array}$ & 99,12 & 100 & 99,99 & 100 & 98,07 \\
\hline $\begin{array}{l}\text { Gasto governamental em saúde como \% dos gastos atuais em } \\
\text { saúde }\end{array}$ & 42,28 & 58,02 & 25,43 & 56,95 & 53,8 \\
\hline $\begin{array}{l}\text { Proporção da população vinculada à serviços nacionais, } \\
\text { sociais, privados ou esquemas de microcobertura de saúde } \\
\text { (2017) }\end{array}$ & $95 \%$ ou mais & 10 a $40 \%$ & Menos de 10\% & 70 a $95 \%$ & $95 \%$ ou mais \\
\hline
\end{tabular}

Fonte: Elaboração própria a partir de dados do Banco Mundial; Organização das Naç̃̃es Unidas (Inter-agency Group for Child Mortality Estimation); Organização Mundial da Saúde.

Índia e África do Sul possuem as expectativas de vida mais baixas dentre os BRICS, bem como as maiores taxas de mortalidade infantil, com valores discrepantes em relação aos demais países. A Índia apresenta os menores gastos governamentais em saúde e o menor gasto proporcional ao PIB, enquanto Brasil e África do Sul são os que mais investem em saúde proporcionalmente ao PIB. Nesse indicador, os BRICS investem bem menos que a média das nações do G7¹6.

Em relação à proporção da população afiliada a serviços de saúde, a China e a Índia apresentam percentuais muito baixos. Esse dado chama a atenção devido ao papel de destaque que ambos os países desempenham na produção e distribuição global de medicamentos genéricos, o que poderia favorecer a robustez de sistemas de saúde nesses dois países, com acesso garantido a medicamentos. A indústria farmacêutica indiana é a terceira maior do mundo em volume, com receitas anuais de US\$38 bilhões e com predomínio de empresas de produtos genéricos ${ }^{17}$. Em nível global, a Índia é o maior fornecedor de genéricos. Mesmo assim, a disponibilidade de medicamentos ainda é um desafio no País. Estima-se que 50 a $80 \%$ da população não consiga acessar 
todos os medicamentos que precisa ${ }^{\mathbf{1 8}}$. Esse é um fator relevante de vulnerabilidade, pois a segurança sanitária está diretamente relacionada ao acesso universal à saúde.

Tabela 2. Impacto de doenças selecionadas (HIV/Aids, TB e câncer) em 2018

\begin{tabular}{lrrrrr}
\hline Dado & Brasil & China & Índia & Rússia & África do Sul \\
\hline Pessoas vivendo com HIV/Aids* & 860.000 & $501.000(2014)$ & 2.100 .000 & 1.000 .000 & 7.200 .000 \\
Mortes por HIV/Aids* & 14.000 & 15.300 & 69.000 & 24.000 & 110.000 \\
Novas infecções por HIV/Aids* & 48.000 & 64.400 & 88.000 & 100.000 & 270.000 \\
Incidência de Tuberculose (TB) & 95.000 & 866.000 & 2.690 .000 & 79.000 & 301.000 \\
Taxa de mortalidade por TB & 6.700 & 39.400 & 449.700 & 10.500 & 63.000 \\
Número de novos casos de & 559.371 & 4.285 .033 & 1.157 .294 & 543.045 & 107.467 \\
câncer & & & & & 57.373 \\
Número de mortes por câncer & 243.588 & 2.865 .174 & 784.821 & 314.611 & \\
\hline
\end{tabular}

Fonte: Elaboração própria a partir de dados da Unaids, OMS, Avert.

*Dados de 2017.

Entretanto, na busca por reduzir suas vulnerabilidades em saúde, os países do BRICS têm assumido compromissos com o acesso a tratamentos e com o enfrentamento de doenças de alto impacto epidemiológico e social ${ }^{19}$. A tabela 2 mostra dados relevantes a respeito de doenças específicas, considerando que hoje os países BRICS, além de lidar com uma alta carga de doenças infecciosas, também observam o aumento da carga de doenças crônicas associadas ao envelhecimento da população e à crescente urbanização.

Para lidar com essas doenças, muitas vezes, os países BRICS não dispõem do controle dos bens estratégicos necessários à prevenção, diagnóstico e tratamento, comercializados por empresas estrangeiras. Também são observadas deficiências em Pesquisa e Desenvolvimento (P\&D) para tais doenças, que causam uma carência de saberes estratégicos e um quadro de vulnerabilidade.

Em relação à Tuberculose (TB), cabe destacar que os países BRICS estão todos na lista dos 20 países de mais alta carga da doença e, somados, reúnem $50 \%$ dos casos no mundo 20 . Além disso, China, Índia e Rússia são os países com o maior número de casos $-47 \%$ do total de casos globais - de tuberculose resistente a medicamentos, condição considerada pela Organização Mundial da Saúde (OMS) como uma emergência de saúde global. Para a OMS, a tuberculose não é uma doença negligenciada e sim uma ‘doença infecciosa de alto impacto', que está entre as 'três grandes' junto com HIV e Malária. Desde 2014, a tuberculose se tornou a mais mortal dentre as infecciosas ${ }^{21}$.

Em relação aos esforços de P\&D, os BRICS ainda não apresentam investimentos à altura do impacto da doença em seus países. Essa lacuna se torna ainda mais expressiva perante os investimentos massivos dos EUA em P\&D para tuberculose, cujo volume é maior que o de todos os outros países do mundo somados e chegou a US\$316 milhões em 2016. Na lista dos dez países que mais investiram em P\&D para tuberculose em 2016, os únicos BRICS que aparecem são a Índia, na sexta posição (U\$14 milhões), e a África do Sul, na décima posição (U\$6 milhões) 22 .

Cabe notar que, mesmo com o grande investimento estadunidense, o investimento global em P\&D para TB permanece abaixo das metas internacionais da OMS, que estipulou como ideal o investimento de US $\$ 2$ bilhões por ano. 
Em 2017 foram investidos apenas US $\$ 772$ milhões. Os EUA foram responsáveis por $40 \%$ do total ${ }^{23}$. Nota-se que os EUA possuem baixa carga e mortalidade de tuberculose. Ainda assim, do ponto de vista estratégico, é considerada uma doença prioritária, como mostrado na seção anterior. Para superar tais assimetrias, a atuação coordenada do BRICS em P\&D em tuberculose constitui uma grande oportunidade.

Os países do BRICS são vistos como alvos prioritários das empresas farmacêuticas devido ao seu potencial de crescimento e consequente lucratividade. De acordo com o
Instituto IQVIA, a China constitui o mercado mais atrativo, com mais de US $\$ 100$ bilhões em vendas em 2014, seguida por Brasil, Índia e Rússia, que estão na faixa dos US\$15 bilhões. Por fim, a África do Sul, na lista dos países com até US $\$ 1$ bilhão em vendas ${ }^{24}$. Na tabela 3 , são reunidos alguns dados relevantes para caracterizar o tamanho dos mercados farmacêuticos dos BRICS, bem como o nível de dependência em relação a produtos farmacêuticos importados ou patenteados, o que revela um desafio, mas ao mesmo uma oportunidade para que encontrem conjuntamente menor vulnerabilidade em segurança de saúde.

Tabela 3. Mercado farmacêutico nos países BRICS em 2016

\begin{tabular}{lccccr}
\hline Dado & Brasil & China & Índia & Rússia & África do Sul \\
\hline $\begin{array}{l}\text { Vendas farmacêuticas (estima- } \\
\text { tiva em bilhões de US } \$ \text { ) (a) }\end{array}$ & $\$ 18.38$ & $\$ 115.46$ & $\$ 17.45$ & $\$ 15.42$ & $\$ 2.91$ \\
$\begin{array}{l}\text { \% de vendas de produtos far- } \\
\text { macêuticos importados (b) }\end{array}$ & 34.76 & 17.9 & 9.68 & 57.79 & - \\
$\begin{array}{l}\text { \% do gasto com medicamentos } \\
\text { patenteados (c) }\end{array}$ & 47.4 & 22.1 & 9.3 & 21.7 & 53.7 \\
\hline
\end{tabular}

Fonte: Elaboração própria a partir de relatórios do US Department of Commerce' (a e c), e de Rodwin, Fabre, Ayoub (b) ${ }^{\mathbf{1 6}}$.

A tabela 3 demonstra que Índia, Rússia e China tem os três menores percentuais de compra de medicamentos patenteados. Essa dinâmica tem relação com o regime de propriedade intelectual adotado em cada país, na medida em que favorece em maior ou menor grau a concessão de patentes farmacêuticas. A Índia, por exemplo, que apresenta o menor percentual de gastos com medicamentos patenteados, possui diretrizes de exame que favorecem a rejeição da maior parte dos pedidos de patente solicitados por grandes empresas farmacêuticas transnacionais. Essa postura defensiva, no entanto, não passa despercebida.

Apesar de o Acordo Trips (Trade-Related Aspects of Intellectual Property Rights) e de a Declaração de Doha possibilitarem certas liberdades no estabelecimento das margens de aplicação dos direitos de propriedade intelectual, os EUA utilizam instrumentos de sua política comercial para classificar determinados países como violadores desses direitos, questionando suas opções políticas e regulatórias. Entre 2011 e 2018, Índia, Rússia e China foram ininterruptamente colocadas na lista prioritária de observação 301 do Escritório de Representação Comercial dos EUA (USTR), criada para pressionar países que supostamente não respeitam direitos de propriedade intelectual.

O Brasil também aparece no mesmo período, mas na lista de observação e não na lista prioritária. A África do Sul, que tem mais da metade de seu gasto farmacêutico baseado em produtos patenteados, não é citada em nenhuma das duas listas nesse período. As considerações feitas pela seção 301 podem se desdobrar em investigações que aumentam a 
pressão sobre os supostos infratores. Entre 1974 e 2018, os EUA iniciaram oito investigações contra o Brasil, seis contra a China, cinco contra a Índia e uma contra a Rússia, segundo dados da Organização Mundial do Comércio (OMC) ${ }^{25}$.

A tabela 3 evidencia também que a China é o mercado mais atrativo dentre os países do BRICS. Em 2018, o total de vendas farmacêuticas na China chegou a US\$219 bilhões, valor que levou a um aumento das vendas de produtos patenteados em comparação com 2016, chegando a US\$30 bilhões ${ }^{26}$. No entanto, essa pode ser considerada uma proporção relativamente baixa. Esses dados podem servir de referência para a compreensão de ofensivas recentes dos EUA contra a China, à qual acusa de proteção insuficiente da propriedade intelectual, tais como: uma investigação iniciada em 2017, por meio da seção 301, a respeito do regime de propriedade intelectual da China sob alegação de 'práticas econômicas injustas' e a requisição, em 2018, pelo estabelecimento de um painel no Sistema de Solução de Controvérsias da OMC, acusando a China de violar o Acordo Trips ${ }^{27 .}$

Essas pressões sobre Pequim podem ter contribuído para as concessões que a China fez em propriedade intelectual na primeira etapa do Acordo Comercial entre EUA e China, firmada em janeiro de 2020. Algumas dessas concessões têm impacto direto na área biofarmacêutica, tais como medidas que estendem o prazo de patentes, medidas que aumentam proteções relacionadas à exclusividade de dados clínicos de medicamentos de marca, medidas de proteção a segredos industriais e medidas de linkage, que criam uma vinculação entre a patente e o registro sanitário. Todas elas dificultam o desenvolvimento e a comercialização de genéricos por empresas chinesas.

A intensificação dos regimes de propriedade intelectual nos BRICS, de maneira geral, não tem apresentado vantagens estratégicas consideráveis. Em levantamento realizado por Sampath e Park ${ }^{\mathbf{2 8}}$, reunindo dados de Brasil, China e Índia, concluiu-se que a ampliação da proteção patentária nesses países está associada com o aumento da remessa de lucros das afiliadas de empresas americanas e com maior poder de mercado delas. Mas a contrapartida esperada, que seria o aumento de intensidade nas atividades de $\mathrm{P} \& \mathrm{D}$ dessas afiliadas, não foi observada, pois justamente o poder de mercado elevado desestimula um ambiente competitivo para a inovação. A pesquisa levou em conta os setores farmacêutico, químico e de tecnologia da informação.

Para reduzir o quadro de dependência de empresas biofarmaceuticas estrangeiras, todos os países BRICS têm adotado estratégias de produção local de medicamentos. Esses países possuem em geral a infraestrutura necessária e a capacidade de produzir genéricos de vários medicamentos essenciais, de modo a atender sua demanda interna e apoiar outros países em desenvolvimento ${ }^{29}$. Brasil, Índia e China, por exemplo, vinham liderando a fabricação de princípios ativos, medicamentos e vacinas de baixo custo $^{30}$. O Brasil fabrica localmente a maior parte das vacinas usadas na elevada cobertura vacinal de seu sistema público de saúde. A Índia possui uma sólida indústria de genéricos e é considerada a 'farmácia dos países em desenvolvimento' devido à sua capacidade de exportar medicamentos a preços baixos. A China é o maior produtor global de Ingredientes Farmaceuticamente Ativos (IFAs), desempenhando, portanto, um papel estratégico na cadeia produtiva global de medicamentos genéricos e de marca.

A Rússia está expandindo a capacidade de suas empresas locais e garantir que a produção local seja responsável por $50 \%$ dos medicamentos em circulação no País, sendo que nos últimos anos cerca de 30 novas plantas farmacêuticas foram construídas e mais de 100 moléculas entraram em estudos clínicos ${ }^{31}$. A África do Sul ainda apresenta um quadro de dependência e possui poucas empresas com musculatura para competição internacional, mas tem investido para atender aos padrões internacionais de boas práticas de fabricação. Os BRICS, portanto, detêm expertise com estratégias para reduzir custos de produção de medicamentos essenciais com vistas 
à ampliação e manutenção do acesso universal a tratamentos. No entanto, observa-se atualmente alguns casos de fusão e aquisição de empresas dos países BRICS por empresas transnacionais estadunidenses e europeias ${ }^{29,32}$. A combinação desses processos de concentração global de mercados e tecnologias, com a desnacionalização de indústrias, tende a gerar vulnerabilidades de segurança de saúde dos países do BRICS ${ }^{33}$.

Cabe notar que, apesar das fusões \& aquisições e das pressões dos EUA em propriedade intelectual, a China ainda detém uma posição estratégica na área biofarmacêutica, por ser o maior produtor global de IFAs e um dos maiores produtores de genéricos. Cerca de $13,4 \%$ das importações dos EUA de medicamentos e produtos biológicos vem da China, sendo que em algumas áreas estratégicas, como antibióticos, cerca de $80 \%$ do abastecimento dos EUA vem da China. Essa 'dependência' dos EUA em relação à China tem sido apontada pelo congresso americano como uma grande ameaça de segurança nacional, tendo em vista o contexto de guerra comercial entre os dois países. Em relatório de uma comissão especial sobre as relações EUA-China, os parlamentares alertam para a possibilidade de Pequim "usar a dependência dos EUA em relação à China como uma arma econômica e cortar o abastecimento de medicamentos de alta importância"34(248). No contexto de pandemia de Covid-19, reveladas as dependências de importações de equipamentos de proteção individual e aparelhos respiradores, tal percepção de vulnerabilidade à segurança de saúde foi reforçada.

\section{O potencial de superação das vulnerabilidades dos BRICS}

Desde 2011, o BRICS realizou nove cúpulas ministeriais e seis reuniões de ministros da saúde, além de quatro eventos paralelos nas Assembleias Mundiais de Saúde (AMS). Além disso, apresentaram diversos posicionamentos conjuntos em saúde em ocasiões como o Conselho Executivo da OMS, os debates das AMS e as reuniões de Alto Nível da Organização das Nações Unidas (ONU) sobre saúde. Vale destacar que, desde 2011, o tema da saúde esteve presente em oito das nove declarações de cúpulas presidenciais do Bloco e que, no campo da Ciência e Tecnologia, a saúde tem sido um dos eixos preferenciais de cooperação. $\mathrm{O}$ tema da saúde aparece ainda com destaque na 'Estratégia de Longo Prazo para os BRICS'35, publicada em 2017 pelo Conselho de ThinkThanks do BRICS. Esses dados revelam a busca por uma cooperação em saúde cada vez mais sólida que, na perspectiva do conflito estrutural, poderia se chocar contra os interesses das grandes empresas e Estados que dominam o setor.

Antes mesmo da conformação do BRICS como Bloco, alguns membros, como Brasil, Índia e África do Sul, tiveram papel-chave em contrabalancear uma agenda imposta por países desenvolvidos focada na maximização dos direitos de propriedade intelectual, em especial no setor farmacêutico. Esses países foram lideranças importantes na aprovação da Declaração de Doha, cunhada como instrumento de garantia de que não sofreriam penalidades da OMC relacionadas ao Acordo Trips por responder a crises de saúde ${ }^{36}$. A partir dessa conquista, tais países, e posteriormente os BRICS como Bloco, realizaram esforços para ampliar a crítica à agenda maximalista de propriedade intelectual e impulsionar a agenda do uso de flexibilidades em defesa da saúde pública ${ }^{37}$.

$\mathrm{Na}$ 'Estratégia de Longo Prazo para os BRICS' $^{35}$, as propostas relacionadas à propriedade intelectual consistem em promover plena implantação das flexibilidades, tais como licença compulsória, importação paralela e produção local de medicamentos e vacinas. A Estratégia também propõe que o número de patentes concedidas na área farmacêutica deve ser limitado por meio de critérios mais rigorosos sobre o que pode ser considerado patenteável. 
Em relação a $\mathrm{P} \& \mathrm{D}$, os BRICS também possuem grandes potencialidades. Em números gerais, os BRICS concentram $17 \%$ dos investimentos globais em P\&D e $27 \%$ dos artigos científicos publicados em revistas internacionais ${ }^{35}$. No setor saúde, a performance em $P \& D$ dos BRICS pode ter um papel decisivo, por ser esse um setor de relevância estratégica e de interconexão com as esferas econômica e militar.

Todos os países BRICS estão qualificados no conceito de 'País em Desenvolvimento Inovador' (IDC), proposto por Morel e atualizado em 2018 ${ }^{38,39}$. Essa categoria é baseada num ranking de inovação que considera o número total de patentes solicitadas por país via PCT e índice GNI per capita daquele país. De acordo com Vasconcellos et al. ${ }^{39(3)}$,

Os IDCs têm a capacidade de desenvolver, produzir, garantir a segurança e comercializar novos produtos de saúde e de desenvolver, testar e introduzir novas políticas e estratégias de saúde.

Segundo o ranking atualizado, os IDCs são: China, Índia, Rússia, Turquia, Brasil, África do Sul, México e Malásia.

De acordo com o relatório G-Finder ${ }^{40}$, a grande maioria (95\%) dos recursos públicos investidos em P\&D para prioridades globais de saúde por países de baixa e média renda vieram de três IDCs: Índia (US\$76 milhões, $72 \%$ ), África do Sul (US\$14 milhões, 13\%) e Brasil (US\$9,2 milhões, 8,8\%). O nível de investimentos públicos realizados pela Índia é notável, mesmo considerando-se países de todas as faixas de renda, o País alcançou a $4^{\mathrm{a}}$ posição geral e foi responsável pelo maior investimento público já registrado dentre os países de renda média e baixa.

Já a África do Sul, se destaca por ser o país com maior investimento em $\mathrm{P} \& \mathrm{D}$ em proporção ao PIB. Não apenas isso, o investimento da África do Sul em 2017, que registrou crescimento de $24 \%$ em relação ao ano anterior, foi o maior já realizado por um país de renda média e baixa, considerando-se essa métrica específica. O Brasil apresentou queda de $42 \%$ nos investimentos em $\mathrm{P} \& \mathrm{D}$ devido a políticas que limitaram os gastos públicos. Essa redução foi gerada especialmente pela redução de $72 \%$ em investimentos do Banco Nacional de Desenvolvimento Econômico e Social (BNDES) e de 67\% da Fundação de Amparo à Pesquisa do Estado de São Paulo (Fapesp) ${ }^{\mathbf{4 0}}$.

No tema P\&D, os BRICS também sinalizam ações conjuntas e cooperação científica, especialmente para doenças como HIV/Aids e Tuberculose. Certamente não é possível considerar intenções e compromissos assumidos em declarações dos BRICS como resultados efetivos. No entanto, análises independentes apontam que em relação a compromissos prioritários em saúde assumidos nas declarações presidenciais, existe uma alta taxa de efetivação de ações concretas pelo conjunto dos países. Em 2014, essa taxa foi de $80 \%$; em 2015 , ficou entre $60 \%$ e $70 \%$; em 2016 , foi de 70\%; e, em 2017 e 2018 , foi de $100 \%{ }^{\mathbf{4 1}}$.

Um caso exemplar é a tuberculose, que constitui um eixo prioritário de ação conjunta dos BRICS e está presente em diversas declarações. Nota-se que desde a cúpula ministerial de saúde de 2014, quando os BRICS adotaram um plano de cooperação em Tuberculose, incrementado nas cúpulas seguintes, com ênfase na cooperação em $\mathrm{P} \& \mathrm{D}$, diversas iniciativas concretas foram anunciadas, em nível nacional e a nível do Bloco.

Em 2015, o Brasil estabeleceu uma 'Estratégia nacional de pesquisa em TB', com base na experiência de sua 'Rede de Pesquisa em Tuberculose' (Rede-TB), uma coalizão que reúne universidades, grupos de pesquisa, gestores e sociedade civil. Já a África do Sul, incluiu a Tuberculose como uma área prioritária de pesquisa dentro da iniciativa 'Parcerias Estratégicas para Inovações em Saúde', gerenciada pelo Conselho de Pesquisa Médica da África do Sul (SAMRC). Em 2016, o governo da Índia lançou um Consórcio de Pesquisa em TB, focado no desenvolvimento de novas ferramentas de combate à doença. A iniciativa canalizou investimentos expressivos, segundo o G-Finder ${ }^{40}$. O Conselho Indiano 
de Pesquisa Médica (ICMR) aumentou seu investimento em $47 \%$ em 2017, atingindo seu maior volume de financiamento já registrado.

A Rússia, por sua vez, em articulação com a OMS, sediou a primeira Conferência Ministerial pelo fim da tuberculose em novembro de 2017. Na ocasião, o presidente russo anunciou um investimento de US $\$ 15$ milhões até 2020 para a cooperação Rússia-OMS pela luta global contra a tuberculose ${ }^{42}$. A China estabeleceu um Consórcio de Pesquisas Clínicas em Tuberculose (CTCT) visando a liderar os esforços do País em pesquisa clínica de alta qualidade em diagnósticos, vacinas e tratamentos para tuberculose ${ }^{\mathbf{4 3}}$.

No âmbito do Bloco, foi anunciada em novembro de 2017 , na cúpula presidencial, a decisão de criar oficialmente a Rede dos BRICS de Pesquisa em Tuberculose - uma proposta já previamente aprovada pelos ministros da saúde. A Rede dos BRICS possui um termo de referência, um secretariado, que já realizou seis reuniões presenciais entre 2018 e 2019, desenvolveu um Programa Colaborativo de Pesquisa, no qual o Brasil, inclusive, já lançou um edital no final de 2019, e tem sido frequentemente mencionada como uma referência para o avanço da $\mathrm{P} \& \mathrm{D}$ em tuberculose, inclusive em documentos oficiais da OMS, como o Relatório Global de Tuberculose de $2018^{21}$.

Além disso, uma análise da cooperação intra-BRICS em ciência, tecnologia e inovação revela que nos três editais lançados entre 2016 e 2019 para financiar pesquisas em diversas áreas, em média $26 \%$ dos projetos aprovados são na área de saúde. Esses editais exigem que cada projeto tenha pesquisadores de, no mínimo, três países diferentes do Bloco. Esses exemplos revelam que a cooperação em saúde não é meramente retórica e já envolve instrumentos de cooperação e investimentos financeiros. Nesse sentido, a declaração da cúpula ministerial de 2019 realizada no Brasil mencionou pela primeira vez a intenção de explorar a possibilidade do NDB financiar projetos em saúde que beneficiem a população dos BRICS.

\section{Os BRICS e a governança global em saúde}

Desde a I Reunião dos Ministros de Saúde dos BRICS, em julho de 2011, o Bloco discutiu e coordenou posições sobre questões de interesse comum. O documento dessa reunião já apontava para uma agenda que envolve: a contínua colaboração para promover sistemas universais de saúde, com acesso a medicamentos, bens e serviços públicos; a função do BRICS como fórum de cooperação e debate sobre questões internacionais na área da saúde; a pré-qualificação de medicamentos dos países BRICS, especialmente aqueles relacionados ao HIV/ Aids, tuberculose e malária; o esforço para que acordos bilaterais e regionais não comprometam as flexibilidades do Trips; o compromisso com a Declaração de Doha. Assim, o BRICS trouxe uma visão política, econômica e social da saúde, e, em vez de moldar suas ações por meio da perspectiva de 'ajuda', como fazem os EUA e demais países da Organização para a Cooperação e Desenvolvimento Econômico (OCDE), trabalha com a 'cooperação' ou com a 'assistência para o desenvolvimento', uma postura diferenciada. Tal agenda seguiu e foi se ampliando, como vimos ao longo do artigo ${ }^{7}$.

Na declaração presidencial de 2017, os BRICS afirmaram que concordam em "impulsionar o papel dos BRICS na governança da saúde global, especialmente no contexto da OMS e agências da ONU"4(2). Também se comprometem com a "Pesquisa e Desenvolvimento e o acesso a medicamentos, vacinas e diagnósticos de baixos preços, de qualidade, efetivos e seguros"4(2). Esses compromissos, presentes desde suas primeiras reuniões, sintetizam as ambições dos BRICS e sua agenda central de conciliação de estratégias de inovação e acesso não só aos países do Bloco, mas a todos os países em desenvolvimento.

Historicamente, a agenda de defesa do acesso a medicamentos tem sido liderada por Índia, Brasil e África do Sul, que se firmaram como referências no campo da diplomacia em saúde, inclusive no âmbito do Fórum de Diálogo Índia-Brasil-África do Sul (Ibas). 
Adicionalmente, China e Rússia, que têm maior peso político e militar no sistema interestatal, têm mostrado que também encaram a saúde como um fator de projeção internacional.

Muitos analistas apontam uma forte vinculação da Iniciativa Belt and Road (Obor) com um crescente papel da China na saúde global. Levando-se em conta a atuação da China na resposta a emergências e surtos, na construção de unidades médicas em outros países, na exportação de tecnologias e conhecimentos médicos e no engajamento em fóruns multilaterais que discutem saúde como o G20 e o BRICS, fica evidente que a saúde será um eixo importante na estratégia geopolítica que está por trás do Obor. Em discurso em Pequim, em novembro de 2016, a então Diretora-Geral da OMS, Margareth Chan, comentou que via grande potencial de a iniciativa se mover para cooperação no enfrentamento de doenças cardíacas, diabetes e câncer ${ }^{44}$.

Já a Rússia, se tornou anfitriã frequente de encontros de alto nível em saúde, começando em 2011 com a Primeira Conferência Ministerial Global em Estilos de Vida Saudáveis e Controle das Doenças Crônicas. Em 2013, a Rússia também desempenhou papel-chave no estabelecimento da Força Tarefa Interagência, liderada pela OMS e voltada para Prevenção e Controle das Doenças Crônicas, inclusive provendo financiamento. Essa Força Tarefa já realizou missões em mais de 20 países.

Em suas cúpulas ministeriais, o Bloco tem reiteradamente se comprometido a fortalecer e legitimar a OMS como a autoridade central nos assuntos de saúde global. Na declaração da Cúpula Ministerial de Saúde de 2017, por exemplo, os BRICS afirmaram o compromisso com a natureza intergovernamental da OMS, mantendo a "integridade, objetividade, supremacia e liderança da OMS na arena da saúde global"4(2). Esse tipo de declaração é uma resposta ao chamado processo de reforma da OMS, que inclui propostas que aumentam a influência de atores não governamentais na definição de prioridades e implantação de ações. Tal reforma se relaciona, em parte, com uma tendência de redução de financiamento da OMS, que tem gerado uma dependência maior de fontes não-estatais. O BRICS tem enfatizado a necessidade de manter a supremacia dos Estados Membros nos processos decisórios e tem cobrado transparência em relação ao engajamento da OMS com atores não estatais ${ }^{19}$.

Também cabe notar que os BRICS têm um papel relevante no financiamento da OMS por meio de contribuições fixas, que são as quotas pagas pelos Estados Membros de maneira proporcional à sua população e riqueza ${ }^{45}$. Em 2018, a China ocupou o primeiro lugar em valor de contribuições fixas, com US\$16 milhões, seguido do Brasil com US $\$ 5,9$ milhões, da Rússia com US $\$ 4,4$ milhões e da Índia com US $\$ 0,67$ milhão ${ }^{19}$. No contexto da pandemia, a China fez duas doações extras para a OMS, para apoiar os esforços de combate à doença, totalizando US\$50 milhões. O Brasil, por sua vez, tem uma dívida acumulada de cerca de US\$33 milhões por não ter pago suas contribuições de 2019 e 2020.

Para melhor caracterizar o alinhamento político dos BRICS, analisamos as nove declarações das cúpulas ministeriais de saúde, os seis comunicados de ministros da saúde emitidos nas assembleias mundiais de saúde e as nove declarações presidenciais emitidas entre 2011 e 2019 e identificamos temas que foram reiterados de forma consistente sob as distintas presidências do Bloco e sob distintos governos em cada país: 1) Uso de flexibilidades do regime de propriedade intelectual para assegurar acesso a medicamentos, 2) Esforços de inovação, especialmente buscando alternativas aos modelos de inovação que hoje favorecem as grandes empresas do norte global;3) Tuberculose, considerado um desafio comum para todos os países devido à carga da doença e às lacunas que ainda persistem na resposta; 4) O papel da OMS na governança global de saúde e os debates sobre reformas que ampliam a influência de atores não-estatais, em especial do setor privado. $\mathrm{Na}$ tabela 4 , são quantificadas as vezes em que cada um desses temas aparece em diferentes tipos de declarações emitidas pelos BRICS. 
Tabela 4. Temas de destaque em declarações do BRICS (2011-2019)

\begin{tabular}{|c|c|c|c|c|c|}
\hline Declarações & Total & $\begin{array}{r}\text { Flexibilidades do } \\
\text { Trips e acesso a } \\
\text { medicamentos }\end{array}$ & $\begin{array}{r}\text { Novos regimes } \\
\text { de inovação }\end{array}$ & Tuberculose & $\begin{array}{r}\text { Reforma da } \\
\text { OMS }\end{array}$ \\
\hline Cúpulas Ministeriais de Saúde & 9 & 9 & 8 & 9 & 6 \\
\hline $\begin{array}{l}\text { Reuniões de Ministros nas Assem- } \\
\text { bleias Mundiais de Saúde }\end{array}$ & 6 & 6 & 6 & 4 & 6 \\
\hline Cúpulas presidenciais & 9 & 3 & 5 & 5 & 0 \\
\hline
\end{tabular}

Fonte: Elaboração própria a partir dos documentos das cúpulas e reuniões citadas.

No tema da inovação, além de propor ações conjuntas e cooperação em P\&D para doenças como HIV/Aids e TB, os BRICS convergem com posicionamentos que apontam as limitações e falhas do sistema de patentes em relação à inovação e defendem novas abordagens e princípios, tais como: 'promover transparência em relação a custos de $P \& D$ e estabelecimento de preços de medicamentos', 'priorizar necessidades específicas de P\&D dos países em desenvolvimento', adotar 'abordagens inovadoras e aprimoradas em P\&D' e 'aplicar o princípio norteador da desvinculação dos custos da P\&D do preço dos produtos de saúde'4.

Cabe notar que o princípio da 'desvinculação' ganhou destaque a partir do relatório do Consultative Expert Working Group on Research and Development (CEWG) da OMS, lançado em 2012, mas sofreu forte oposição das grandes empresas farmacêuticas e seus Estados sedes, justamente por romper com a base do sistema de inovação baseado em patentes. Os BRICS afirmam que o princípio da desvinculação é uma estratégia para garantir "acesso equitativo e a preços baixos a medicamentos, vacinas, diagnósticos e outros produtos médicos seguros, efetivos e de qualidade, incluindo genéricos"4(2).

Conforme já mencionamos, promover o acesso a medicamentos, vacinas, diagnósticos e outros produtos médicos é uma prioridade declarada do Bloco. Nesse sentido, os BRICS reiteradamente pautam a 'aplicação plena' das flexibilidades do Trips para proteger interesses de saúde pública. Também é frequente a afirmação de que vão atuar conjuntamente para 'proteger o espaço político contra medidas Trips-plus e outras medidas que impedem o acesso a medicamentos'. Sobre esse tema, é importante mencionar ainda que as declarações dos BRICS contêm referências a processos de negociação onde há uma oposição explícita entre países em desenvolvimento e países desenvolvidos, como, por exemplo, a Estratégia Global e Plano de Ação em Saúde Pública, Inovação e Propriedade Intelectual (GSPOA), o Relatório do Grupo CEWG, da OMS, e o relatório e recomendações do Painel de Alto Nível da ONU sobre Acesso a Medicamentos ${ }^{4}$.

A GSPOA é considerada uma vitória da diplomacia em saúde de países dos BRICS, pois aponta falhas do sistema de propriedade intelectual e defende novas abordagens para inovação e o uso de flexibilidades do Trips. $\mathrm{O}$ CEWG veio na esteira da GSPOA e fez propostas concretas de princípios que deveriam nortear a inovação, como a desvinculação. Já o Painel de Alto Nível trouxe novamente à tona propostas que alteram as premissas básicas do sistema de patentes, capazes de modificar regras que garantem a concentração do mercado farmacêutico nas mãos de empresas estadunidenses e europeias. Essas negociações e relatórios sofreram forte oposição dos EUA e de países europeus, bem como de atores do setor privado. Os posicionamentos dos BRICS em relação à OMS e à flexibilização do Trips são totalmente contrários aos interesses e 
ações dos EUA, que têm por objetivo fortalecer o Trips, inclusive por meio da lista prioritária de observações do USTR mencionada, ou ampliá-lo por meio de acordos bilaterais. Esse antagonismo pode ficar ainda mais explícito do âmbito da pandemia, com China e Rússia contrapondo-se aos EUA.

\section{Os BRICS, a pandemia de Covid-19 e a geopolítica das vacinas}

A pandemia do novo coronavírus, decretada em março de 2020, também pode ter efeitos significativos nas relações entre os países BRICS em busca de segurança sanitária, e no papel do Bloco na governança global. Em abril de 2020, o BRICS, sob presidência russa, declarou que o combate a Covid-19 está na agenda do Bloco. No final de abril, o BRICS realizou uma Conferência Extraordinária de Ministros das Relações Exteriores sobre Covid-19, na qual os países concordaram em intensificar compartilhamento de informações e colaboração em pesquisas de vacinas e medicamentos, e se comprometeram com o reforço do multilateralismo. Em setembro, os ministros se reuniram novamente e emitiram uma nova declaração onde encorajaram a operacionalização do Centro dos BRICS de Pesquisa e Desenvolvimento em Vacinas, proposta que havia sido elaborada na reunião ministerial de saúde de 2018, mas que que nunca saiu do papel ${ }^{4}$.

Os países BRICS também possuem mecanismos de atuação coordenada. Desde 2016, por meio do programa de Cooperação em Ciência, Tecnologia e Inovação, realizam editais conjuntos de financiamento de pesquisa em várias áreas. Em 2020, pela primeira vez, o BRICS lançou um edital com um tema único: Covid-19. Os projetos devem focar em diferentes tecnologias para o enfrentamento da pandemia, incluindo vacinas, e devem envolver ao menos três países do Bloco. Por meio dessa iniciativa, é possível haver um impulso adicional para projetos que já estão em curso em cada um dos países e um estímulo para cooperação concreta entre eles.

Além disso, o NDB estabeleceu uma Unidade de Assistência Emergencial, que disponibilizou um montante de US $\$ 10$ bilhões de apoio aos BRICS na resposta à Covid-19. Já foram aprovados quatro empréstimos emergenciais, no total de US\$4 bilhões, sendo dois para a China, um para a Índia e um para a África do Sul. De acordo com comunicado do Conselho gestor do NDB, esses empréstimos podem ser usados tanto para gastos diretamente relacionados com o enfrentamento da pandemia como para apoiar medidas governamentais de recuperação econômica.

As relações intra-BRICS, no entanto, sofrem algumas conturbações importantes, com destaque para o notável alinhamento do Brasil com os EUA por força de mudanças recentes na política externa brasileira, intensificadas com o governo Bolsonaro. Observa-se a opção do governo brasileiro por um alinhamento automático com os EUA na disputa econômica e política entre EUA e China em áreas tecnológicas estratégicas, com claras implicações militares.

Exemplar nesse sentido é a tentativa do governo brasileiro de reproduzir a postura norte-americana de ataques à OMS. Desde março, o governo estadunidense tem criticado a atuação do órgão, e em julho notificou ao Sistema ONU sua intenção de retirar seu financiamento à OMS. O governo brasileiro, como já mencionado, não está honrando com seu compromisso financeiro com a OMS desde 2019, tem feito declarações que desqualificam as orientações científicas proferidas pelo órgão e cobrado uma investigação sobre as falhas na resposta à pandemia, em claro alinhamento com o governo Trump.

Por outro lado, o Brasil tem se colocado como colaborador da OMS em iniciativas que visam a fortalecer o acesso a medicamentos, diagnósticos e vacinas de forma equitativa em nível global, em alinhamento com as declarações do BRICS. Nesse sentido, o Brasil se 
tornou membro do Conselho de Facilitação da Iniciativa ACT-A, articulada pela OMS com o objetivo de acelerar o desenvolvimento e a distribuição de tecnologias de saúde, e declarou a intenção de participar e investir na iniciativa Covax, que é parte da arquitetura desenvolvida em parceria com a OMS e tem foco na compra e distribuição de vacinas.

O alinhamento entre Brasil e EUA coloca em relevo as diferenças marcantes entre os BRICS, visto que a China é a maior desafiante da supremacia estadunidense, alçando tecnologia de ponta na área de saúde e biotecnológica, enquanto o Brasil possui uma indústria altamente dependente de insumos externos e atualmente busca uma política subalterna aos interesses estadunidenses.

No entanto, não há indícios significativos de isolamento do Brasil no BRICS por conta dessa postura. Em maio de 2020, por exemplo, o Conselho de Governadores do NDB elegeu por unanimidade o brasileiro Marcos Troyjo, então secretário especial de Comércio Exterior e Assuntos Internacionais do Ministério da Economia, como presidente do Banco pelos próximos cinco anos. Além disso, o governo Bolsonaro desenvolveu algumas cooperações bilaterais com membros do Bloco, como, por exemplo, a importação da China de equipamentos de proteção para profissionais de saúde do Sistema Único de Saúde (SUS); a articulação com o governo indiano para receber insumos farmacêuticos, a despeito do bloqueio de exportação que havia sido imposto pelo governo Modi; e uma reunião entre Bolsonaro e Vladimir Putin em junho para aprofundar a cooperação entre Brasil e Rússia no combate à pandemia.

Inegavelmente, o aumento da rivalidade entre China e EUA vai ser um fator decisivo para definir o quão insustentável a postura do Brasil pode se tornar para a coesão interna do BRICS. As polarizações entre EUA e China em relação às instituições multilaterais e à cooperação na distribuição de vacinas e outros bens de saúde estão dando o tom de uma nova ordem de saúde global, com novas distribuições de poder que afetarão a capacidade dos espaços decisórios multilaterais de definir as regras e dará novos contornos ao papel que um Bloco como o BRICS pode desempenhar.

$\mathrm{Na}$ Assembleia Mundial de Saúde, realizada em 18 e 19 de maio de 2020 com foco na crise da Covid-19, China e EUA manifestaram posições absolutamente antagônicas em dois temas centrais: O papel da OMS e o regime de patentes. A resolução sobre combate à Covid19, aprovada pelos 194 Estados membros, fez referência ao uso de flexibilidades do Acordo Trips para garantir 'acesso universal, rápido e equitativo e distribuição justa' de medicamentos, vacinas e outras tecnologias essenciais de saúde. No entanto, os EUA apresentaram uma declaração por escrito na qual se dissociaram dos parágrafos da resolução que tratam das flexibilidades do Trips, alegando que essa linguagem poderia afetar o incentivo para o desenvolvimento de novos produtos. Além disso, o presidente dos EUA, Donald Trump, enviou uma carta ao Diretor-Geral da OMS acusando a instituição de falhas graves.

Já a China, participou da AMS com um discurso oposto. Representada pelo Presidente Xi Jinping, enfatizou a liderança da OMS na resposta global à Covid-19 e convocou aumento do apoio político e financeiro para a instituição. Além disso, declarou que assim que uma vacina for desenvolvida no País, ela será tornada um 'bem público global', ou seja, não estará sob monopólio, de modo a favorecer o acesso em todos os países.

Inegavelmente, a vacina para Covid-19 configura um bem estratégico em torno do qual o tabuleiro geopolítico está se movimentando devido à sua capacidade de gerar prestígio, status e liderança para os países que a obtenham primeiro, além de possibilitar uma maior segurança sanitária e vantagens no processo de 'reativação econômica'. Os esforços para o estabelecimento de uma cooperação internacional na compra e distribuição de vacinas são ainda limitados em termos de captação de recursos e coordenação política. Apesar de ter sido anunciado um consórcio internacional 
de vacinas, o Covax, que teria como missão centralizar negociações com as empresas e distribui-las de forma equitativa entre os países, inclusive os de mais baixa renda, prevalecem acordos bilaterais entre países e empresas, gerando incerteza sobre que estoques restarão para a cooperação internacional. Além disso, o papel da OMS nessa iniciativa é de parceira e não executora, o que revela o avanço de um processo de fragilidade da instituição como espaço de articulação multilateral.

Existem muitos projetos em curso para desenvolvimento de vacinas para Covid-19, mas já se evidencia uma corrida mais acirrada entre instituições e empresas dos EUA, China e Rússia, que se encontram em fase mais avançada de desenvolvimento, além do Reino Unido, que é sede de um dos projetos mais promissores e avançados. Com base em dados disponíveis em setembro de 2020, evidencia-se que tanto China como EUA possuem, cada um, quatro vacinas na etapa final de desenvolvimento clínico, enquanto a Rússia tem uma. Tanto China como Rússia implantaram processos de aprovação emergencial e limitada dessas vacinas, mesmo antes da obtenção de resultados preliminares dos estudos em clínicos definitivos. Os EUA, por sua vez, estabeleceram acordos de compra antecipada das quatro vacinas mais avançadas das empresas estadunidenses e de outras duas vacinas desenvolvidas por empresas europeias. A função desses acordos é garantir acesso prioritário dos EUA às primeiras doses produzidas.

No debate público, se convencionou chamar tal postura de 'nacionalismo das vacinas', onde se aplica uma lógica de supremacia da necessidade nacional frente à necessidade global, o que favorece os países com maior poder econômico ou que são sede das maiores empresas do setor farmacêutico. As posturas de China e Rússia também têm um forte caráter nacionalista e são marcadas por uma clara disputa com os EUA por liderança tecnológica, o que pode significar que decisões científicas e regulatórias venham a ser afetadas pelo ritmo da competição geopolítica. Porém, as estratégias chinesa e russa diferem da norte-americana por incluírem uma agenda mais pronunciada de parcerias de pesquisa e produção com outros países, o que denota uma conexão com pautas da agenda BRICS que abordamos anteriormente, como a transferência de tecnologia, mas também uma estratégia de usar as vacinas como instrumento diplomático e como vetor de aumento do soft power na arena internacional.

No entanto, em relação aos mecanismos multilaterais criados para investir no desenvolvimento de vacinas para emergências globais de saúde, como é o caso da Coalizão para Inovações em Preparação para Epidemias (Cepi), os investimentos se concentram principalmente nas vacinas com origem nos EUA e na Europa. Das nove vacinas de Covid-19 presentes no portfólio do Cepi, cinco têm envolvimento de empresas norte-americanas, duas de empresas europeias, e as outras se referem a projetos com origem no Japão e na Austrália. Portanto, há um desequilíbrio na inserção de vacinas de origem norte-americana nesses mecanismos em comparação com vacinas de origem chinesa e russa.

Apesar de a corrida das vacinas ter como eixo central essa dinâmica entre as três potências do sistema internacional, cabe lembrar que a Índia possui duas vacinas que estão em etapas relativamente avançadas de desenvolvimento e abriga o maior produtor de vacinas do mundo em volume, o Serum Institute of Índia, que já tem acordos para produzir a vacina da AstraZeneca (Reino Unido) e da Novavax (EUA), além de ter parcerias para reforçar a produção das vacinas que estão sendo desenvolvidas no País. Embora não exista nenhum projeto nacional de vacina em fase clínica, o Brasil firmou acordos relacionados a seis vacinas: AstraZeneca (Reino Unido), Sinovac (China), Sinopharm (China), Biontech/Pfizer (EUA), Johnson \& Johnson (EUA) e Gamaleya (Rússia).

No caso da África do Sul, estão confirmados ensaios clínicos com três das vacinas mais avançadas: Moderna, Johnson \& Johnson e AstraZeneca. Esses dados revelam que, 
individualmente, os países do BRICS têm uma inserção relevante na dita 'corrida das vacinas' e dispõem de prévios arranjos diplomáticos, financeiros e institucionais para atuar de forma conjunta. Resta saber se os alinhamentos políticos, presentes nas declarações analisadas neste artigo, serão mais fortes do que as divisões e disputas internas.

Ao menos Brasil e África do Sul estão em algum nível, pautando, por exemplo, o tema das flexibilidades do Acordo Trips. No plano internacional, a África do Sul submeteu no final de julho um documento na OMC demandando uma abordagem mais 'holística' para o uso de flexibilidades do Trips no contexto da pandemia, na qual não apenas patentes, mas também segredos industriais, designs industriais e copyrights estejam sujeitos ao uso de medidas como licença compulsória. Em nível nacional, o Brasil está em um processo avançado de discussão do projeto $1462 / 20$, que estabelece licença compulsória automática para todas as tecnologias comprovadamente eficazes para o enfrentamento da pandemia de Covid-19 e futuras pandemias.

Declarações alinhadas com essa diretriz política também emergiram na Índia e na China. Considere-se, por exemplo, o anúncio feito pelo CEO do Serum Institute of India de que não vai patentear a vacina que está desenvolvendo e que $50 \%$ da produção será para atender à demanda indiana e os outros $50 \%$, à demanda global. Ou, ainda, a declaração do Chanceler chinês em encontro com ministros latino-americanos em julho, quando afirmou que a vacina desenvolvida na China será um bem público de acesso universal, ecoando a declaração do presidente Xi Jiping na Assembleia da OMS.

A pandemia e a corrida pelas vacinas trazem para o primeiro plano uma geopolítica biofarmacêutica ${ }^{\mathbf{4 6}}$, onde está em jogo uma disputa de superioridade tecnológica, com EUA, China e Rússia como principais atores. Está em jogo também a busca por uma segurança sanitária privilegiada, que, no caso dos EUA, se afirma com base na projeção de suas empresas e seus monopólios, gerando uma perspectiva de escassez global e, no caso do BRICS, caminha em paralelo a um discurso de aposta no multilateralismo e numa agenda de diplomacia em saúde, onde há mais espaço para cooperação com outros países, inclusive no abastecimento de vacinas.

\section{Conclusões e considerações finais}

As grandes empresas transnacionais dos países desenvolvidos concentram o mercado farmacêutico global e seus Estados atuam no sentido de promover a maximização dos direitos de propriedade intelectual. Paralelamente, a estratégia estadunidense de segurança nacional no que se refere à saúde aponta claramente que essa área é considerada estratégica. Nesse sentido, apoiar a inovação biomédica, manter a liderança tecnológica e usar o Trips diante da competição geopolítica interestatal, principalmente frente a países do BRICS identificados como rivais, a exemplo de Rússia e China, aparecem como elementos importantes.

Os países do BRICS possuem diferenças marcantes tanto em suas projeções e pretensões políticas internacionais como em seus indicadores socioeconômicos e estrutura de gastos públicos. Entretanto, na busca por reduzir suas vulnerabilidades em saúde, os BRICS têm encarado a atuação coordenada no combate a doenças de alto impacto, como a tuberculose, como uma grande oportunidade.

Conforme evidenciamos, em quase uma década de cooperação em saúde, os BRICS desenvolveram não apenas consistência em alguns posicionamentos sobre temas centrais de saúde global como também iniciaram ações concretas de cooperação que começam a gerar resultados. A estratégia dos BRICS, no entanto, se apoia no papel das instituições multilaterais, que estão num processo acentuado de crise, incorrendo em poder institucional e normativo cada vez mais reduzido da OMS em particular. Ao mesmo tempo, o avanço da cooperação dos BRICS esbarra em tensões internas dos 
países a respeito da sua inserção nas cadeias de valor do mercado farmacêutico, especialmente com a China e a Índia tendendo a reformas de propriedade intelectual que fazem concessões aos interesses dos EUA, bem como em tensões internas entre os países membros, especialmente China e Índia, que disputam mercados farmacêuticos. Além disso, as mudanças na política externa brasileira também acenam como um risco para a coesão do Bloco.

É em meio a essa combinação de potencialidades e fragilidades que os BRICS tentam se articular na resposta à pandemia de Covid-19, aproveitando arranjos institucionais que já haviam sido estabelecidos, como o NDB e os editais de ciência e tecnologia, e reforçando politicamente o papel da OMS, com participação limitada do Brasil. Essas estratégias têm suas limitações e ainda representam uma pequena parcela do potencial de influência que os BRICS poderiam desempenhar na saúde global, levando-se em consideração a falta de ações mais efetivas para dar corpo aos posicionamentos do Bloco a respeito do sistema de patentes e das reformas para transformar o sistema de inovação mais transparente, sustentável e menos controlado por empresas do norte global. Ainda assim, o fato de os países membros do Bloco terem foco na agenda de acesso a medicamentos, produção local e transferência de tecnologia e estarem ativamente envolvidos no desenvolvimento das vacinas para Covid-19, bem como medicamentos e diagnósticos, traz à tona novas oportunidades para o papel do Bloco na resposta a desafios comuns dos países em desenvolvimento.

Do ponto de vista da Economia Política Internacional, a pandemia de Covid-19 intensifica a disputa entre EUA, China e Rússia, tendo a corrida pelas vacinas como um dos vetores mais expressivos, assim como coloca em relevo a importância da segurança em saúde. De fato, a pandemia explicitou disputas que já vinham se desenvolvendo no século XXI, inclusive em relação ao papel da OMS, de um lado, e da OMC, de outro. A primazia de interesses nacionais é intensificada em todas as partes, mas ainda assim o BRICS tem buscado manter sua convergência e cooperação. Ao que tudo indica, esses esforços são insuficientes para reverter a tendência de derrocada do multilateralismo e de aumento das inequidades no acesso à saúde impulsionadas pela agenda estadunidense, embora, ao menos, sirvam para marcar um contraste que vai ser decisivo no longo processo de redefinição das bases do que se convém chamar de saúde global.

\section{Colaboradores}

Padula R (0000-0002-8703-5171)* e Fonseca FCB (0000-0002-1070-0049)* contribuíram igualmente para a elaboração do manuscrito. 


\section{Referências}

1. Almeida C. Saúde, política externa e cooperação sul-sul em saúde: elementos para a reflexão sobre o caso do Brasil. In: Fundação Oswaldo Cruz. A saúde no Brasil em 2030. Rio de Janeiro: Fiocruz; Ipea; Ministério da Saúde; 2013. p. 233-327.

2. Ruckert A, Labonté R, Lencucha R, et al. Global health diplomacy: A critical review of the literature. Soc. Scie. Med. 2016; (155):61-72.

3. Padula R. 'Economia Política Internacional da Saúde, autonomia estratégica e segurança nacional'. Carta Inter. 2017; 12(2):174-196.

4. Brasil. Ministério das Relações Exteriores. Declarações e Comunicados Setoriais. [internet]. [acesso em 2020 jul 20]. Disponível em: http://www.itamaraty. gov.br/pt-BR/component/tags/tag/brics.

5. Carvalho F. O complexo médico-tecnológico-financeiro norte-americano: uma investigação a partir do setor biofarmacêutico. [dissertação]. [Rio de Janeiro]: Universidade Federal do Rio de Janeiro; 2019.

6. Gadelha C, Silveira L. A saúde na política nacional de desenvolvimento: um novo olhar sobre os desafios da saúde. In: Noronha JC, Pereira TR, organizadores. A saúde no Brasil em 2030: desenvolvimento, Estado e políticas de saúde. v. 1. Rio de Janeiro: Saúde Brasil 2030; Fiocruz; 2013.

7. Padula R. A cooperação em saúde no BRICS: uma perspectiva econômica e política brasileira. In: Costa D, Gonçalves W, organizadores. Brasil nos BRICS. Rio de Janeiro: Capax Dei; 2015.

8. McInnes C. Health. In: Williams P, editor. Security Studies, an introduction. London: Routledge; 2008.

9. National Intelligence Council. The Global Infectious Disease Threat and Its Implications for the United States; Washington, DC: Central Intelligence Agency; 2000.
10. National Intelligence Council. Strategic Implications of Global Health. Washington, DC: Central Intelligence Agency; 2008.

11. National Intelligence Council. The Next Wave of HIV/ AIDS: Nigeria, Ethiopia, Russia, India and China. Washington, DC: Central Intelligence Agency; 2002.

12. Padula R. A geopolítica estadunidense e a Eurásia. In: Fiori JL, organizador. Sobre a guerra. Petrópolis: Vozes; 2018.

13. Department of Defense. National Defense Strategy of the United States of America 2018: Sharpening the American Military's Competitive Edge. Washington, DC: DoD; 2018.

14. The Withe House. National Security Strategy of the United States of America. Washington, DC: The White House; 2017.

15. China. Brics Joint Statistical Publication 2017 [internet]. 2017. [acesso em 2020 mar 18]. Disponível em: https://rosstat.gov.ru/free_doc/doc_2017/JSP-2017. pdf.

16. Rodwin VG, Fabre G, Ayoub RF. BRIC Health Systems and Big Pharma: A Challenge for Health Policy and Management. Inter. J. Health Pol. Manag. 2018; 7(3):201-206.

17. Indian Pharmaceutical Alliance. The Indian pharmaceutical industry - the way forward. Mumbai: IPA; 2019.

18. Maiti R, Bhatia V, Padhy B, et al. Essential Medicines: An Indian Perspective. Indian J. commun. med. 2015; 40(4):223-232.

19. Reddy SK, Mazhar S, Lencucha R. The financial sustainability of the World Health Organization and the political economy of global health governance: a review of funding proposals. Glob. Health. 2018; 14(19):1-11. 
20. Brasil. Ministério da Saúde. Manual de Recomendações para o Controle da Tuberculose no Brasil. Brasília, DF: MS; 2019.

21. World Health Organization. Global Tuberculosis Report 2019. Genebra: WHO; 2019.

22. Low M. Which countries invest most in Tb research? [internet] 2017. [acesso em 2020 mar 18]. Disponível em: https://www.spotlightnsp.co.za/2017/12/06/ countries-invest-tb-research/.

23. Treatment Action Group. Tuberculosis Research Funding Trends 2015-2017. New York, TAG: 2018.

24. IQVIA Institute. Report 2018 and Beyond: Outlook and Turning Points. North Carolina: IQVIA; 2018.

25. US Trade Representative. Update concerning China's acts, policies and practices related to technology transfer, intellectual property, and innovation [internet]. 2018. [acesso em 2020 mar 18]. Disponível em: https://ustr.gov/sites/default/files/enforcement/301Investigations/301\%20Report\%20Update.pdf.

26. US Department of Commerce. China Pharmaceuticals [internet]. [acesso em 2020 jul 20]. Disponível em: https://www.export.gov/article?id=China-Pharmaceuticals.

27. World Trade Organization. DS542: China - certain measures concerning the protection of intellectual property rights [internet]. 2018. [acesso em $2020 \mathrm{mar}$ 18]. Disponível em: www.wto.org/english/tratop_e/ dispu_e/cases_e/ds542_e.htm.

28. Sampath PG, Park W. Do Patents Lead to Market Concentration and Excess Profits? GDAE Working Paper 19-02. Massachusetts; TUFTS University; 2019.

29. Ezziane Z. Essential drugs production in Brazil, Russia, India, China and South Africa (BRICS): opportunities and challenges. Inter. J. Health Polic. Manag. 2014; 3(7):365-370
30. Acharya S, Barber S, Lopez-Acuna D, et al. BRICS and global Health. Bulletin of the World Health Org. 2014; 92(6):385-464.

31. Nova Medica. The "Pharma-2030" Strategy: Promoting Globalization [internet]. 2018. [acesso em 2020 mar 19]. Disponível em: https://novamedica.com/ media/smi/p/8691-the-pharma-2030-strategy-promoting-globalization.

32. Gagnon M, Volesky KD. Merger mania: mergers and acquisitions in the generic drug sector from 1995 to 2016. Global Health; 2017; 13(62):1-7.

33. Padula R, Noronha G, Mitidieri T. "Complexo econômico-industrial de saúde, segurança e autonomia estratégica Para Pensar a Inserção do Brasil Frente ao Mundo". Rio de Janeiro: Fundação Oswaldo Cruz; 2015.

34. US-China Economic and Security Review Commission (USCC). Report to Congress [internet]; 2019. [acesso em 2020 jul 20]. Disponível em: https://www. uscc.gov/sites/default/files/2019-11/2019\%20Annual\%20Report\%20to\%20Congress.pdf.

35. BRICS Think Tanks Council. Realizing the BRICS Long-Term Goals [internet]. 2017. [acesso em 2020 mar 19]. Disponível em: https://www.orfonline.org/ wp-content/uploads/2017/08/Brics.pdf.

36. Odell J, Sell SK. Reframing the Issue: The Coalition on Intellectual Property and Public Health in the WTO, 2001. In: Odell J, editor. Negotiating trade: developing countries in the WTO and NAFTA. New York: Cambridge University Press; 2006.

37. Menezes HZ. South-South Collaboration for an Intellectual Property Rights Flexibilities Agenda. Contexto inter. 2018; 40(1):117-138.

38. Morel C, Broun D, Dangi A, et al. Health Innovation in Developing Countries to Address Diseases of the Poor. Innovation Strat. Today. 2005; (1):1-15.

39. Vasconcellos A, Fonseca B, Morel C. Revisiting the concept of Innovative Developing Countries (IDCs) 
for its relevance to health innovation and neglected tropical diseases and for the prevention and control of epidemics. PLoS Neglected Trop. Diseases. 2018; 12(7):1-20.

40. Policy Cures Research. Neglected Disease Research and Development: Reaching new

41. Heights. Sydney: G-Finder Report; 2018.

42. BRICS Research Group. BRICS Johannesburg Summit Final Compliance Report 2018-2019 [internet]. 2020. [acesso em 2020 mar 18]. Disponível em: http:// www.brics.utoronto.ca/compliance/2018-johannesburg-final-compliance.pdf.

43. Center for Strategic and International Studies. Putin and global health: friend or foe? [internet]. 2019. [acesso em 2020 jan 3]. Disponível em: https://www. csis.org/analysis/putin-and-global-health-friend-or-foe.

44. China Tuberculose Clinical Trial Consortium. 4th Annual RePORT International Meeting [internet]. 2018 [acesso em 2020]. Disponível em: https://www.reportinternational.org/sites/default/files/resources/Introduction\%20of\%20China\%20Tuberculosis\%20Clinical\%20Trial\%20Consortium\%20\%28CTCTC\%29. pdf.

45. Nikogosian H. Global health disruptors: The Belt and Road initiative. BMJ 2018; 363(Special supplement on Global Health Disruptors):22.

46. World Health Organization. Contributors [internet]. 2017. [acesso em 2020 mar 19]. Disponível em: http:// open.who.int/2016-17/contributors/contributor.

47. Carvalho F. State-company institutional complementarities on biomedical R\&D in the US and its global consequences. Inter. Relations a Diplo. 2020; 8(4):155172.

Recebido em 18/08/2020

Aprovado em 28/09/2020

Conflito de interesses: inexistente

Suporte financeiro: não houve 